\title{
Extreme thrombocytosis in a traumatic patient
}

\author{
Hyun-Hea Kim ${ }^{1}$, Byung-Sang Lee ${ }^{1}$, Kyoung Seok Kweon ${ }^{1}$, Dae-Eun Kweon ${ }^{1}$, and Tae-Gyu Lee ${ }^{2}$ \\ Department of Anesthesiology and Pain Medicine, ${ }^{1} \mathrm{CHA}$ Gumi Medical Center, CHA University, Gumi, ${ }^{2} \mathrm{CHA}$ Bundang Medical \\ Center, CHA University, Seongnam, Korea
}

Encountering abnormally high values of platelet in patients who do not have a clonal hematologic disease is a phenomenon known as secondary or reactive thrombocytosis, which is considered a normal response after inflammatory insults, such as infection, surgery, or trauma [1]. After trauma, development of thrombocytosis is common, as reported in the prior studies, in which about $20 \%$ of patients had a platelet count above $450,000 / \mu \mathrm{l}$, and with respect of extreme thrombocytosis (platelet count above $1,000,000 / \mu \mathrm{l}$ ), the incidence is approximately $1.4-5.7 \%$ in trauma patients $[1,2]$. The anesthesiologists have to consider whether this condition be managed with anticoagulants to prevent thromboembolic event. We report our experience of perioperative management of a patient with reactive thrombocytosis.

An 83-year-old woman was scheduled for dynamic hip screw fixations for right intertrochanteric fracture. Her medical and surgical histories were uneventful. The baseline laboratory investigations revealed extreme thrombocytosis (platelet count $1,430,000 / \mu \mathrm{l})$, borderline derangement in coagulation parameter (aPTT $46.4 \mathrm{sec}, 1.20 \mathrm{INR}$ ) and marginal leukocytosis. Preoperative electrocardiogram and chest radiograph were unremarkable. Despite the marked thrombocytosis, physical examination revealed no evidence of arterial occlusive disease. We considered the thrombocytosis due to secondary cause - trauma; because the patient experienced trauma, there was no previous medical history, and the C-ractive protein was elevated. We recommended using anticoagulant in the perioperative period because the patient was an old woman with femur fracture, but anticoagulant was not used due to a fear of bleeding tendency. The patient underwent an operation under general anesthesia. The induction of anesthesia was performed with propofol and rocuronium. After a tracheal intubation, the left radial artery was cannulated. Anesthesia was maintained with sevoflurane in $\mathrm{N}_{2} \mathrm{O}$ /oxygen. There was no significant intraoperative event and the recovery from anesthesia was uneventful.

During a perioperative period, we had closely observed the patient to observe whether the deep vein thrombosis or arterial occlusive events developed. There was no thromboembolic complication on the postoperative 9 months follow-up. The platelet count was gradually decresed and laboratory studies demonstrated an normal platelet count $(434,000 / \mu \mathrm{l})$ on the $39^{\text {th }}$ postoperative day.

So, should this condition be managed with anticoagulant to prevent thromboembolic or other events?

If the extreme thrombocytosis is caused by reactive thrombocytosis, there is no evidence showing any benefit to anticoagulant therapy, and then a significantly higher incidence of wound infections was reported in patients who were treated with aspirin, compared with patients who were not [1].

Despite some dissenting reports [3], it is a more common conclusion that secondary thrombocytosis is not elevated risk of thromboembolic complication, patients with reactive thrombocytosis, developing thrombotic complications, had additional risk factors $[4,5]$.

But in the perioperative period, close observation of whether thromboembolic complication occurs, as well as regular monitoring of platelet count is needed. And possibly, anti-coagulation drug for the patients with additional risk factor may be useful.

Corresponding author: Hyun-Hea Kim, M.D., Department of Anesthesiology and Pain Medicine, CHA Gumi Medical Center, CHA University, 855, Hyeonggok-dong, Gumi 730-728, Korea. Tel: 82-54-450-9684, Fax: 82-54-450-9990, E-mail: leiga11@naver.com

(c) This is an open-access article distributed under the terms of the Creative Commons Attribution Non-Commercial License (http:// creativecommons.org/licenses/by-nc/3.0/), which permits unrestricted non-commercial use, distribution, and reproduction in any medium, provided the original work is properly cited. 


\section{References}

1. Saadi Z, Inaba K, Barmparas G, Salim A, Talving P, Plurad D, et el. Extreme thrombocytosis in trauma patients: are antiplatelet agents the answer? Am Surg 2009; 75: 1020-4.

2. Valade N, Decailliot F, Rebufat Y, Heurtematte Y, Duvaldestin P, Stephan F. Thrombocytosis after trauma: incidence, aetiology, and clinical significance. Br J Anaesth 2005; 94:18-23.

3. Salim A, Hadjizacharia P, DuBose J, Kobayashi L, Inaba K, Chan LS, et el. What is the significance of thrombocytosis in patients with trauma? J Trauma 2009; 66: 1349-54.

4. Griesshammer M, Bangerter M, Sauer T, Wennauer R, Bergmann L, Heimpel H. Aetiology and clinical significance of thrombocytosis: analysis of 732 patients with an elevated platelet count. J Intern Med 1999; 245: 295-300.

5. Ghaffari S, Pourafkari L. Acute myocardial infarction in a patient with post-splenectomy thrombocytosis: a case report and review of literature. Cardiol J 2010; 17: 79-82. 